\title{
Multiple traumatic limb loss: A comparison of Vietnam veterans to OIF/ OEF servicemembers
}

\author{
Paul J. Dougherty, MD; ${ }^{*}$ Lynne V. McFarland, PhD; ${ }^{2}$ Douglas G. Smith, MD; ${ }^{3}$ Alberto Esquenazi, MD; ${ }^{4}$ \\ Donna Jo Blake, MD; ${ }^{5}$ Gayle E. Reiber, MPH, $\mathbf{P h D}^{2}$ \\ ${ }^{1}$ Department of Orthopaedic Surgery, University of Michigan, Ann Arbor, MI; ${ }^{2}$ Health Services Research and Develop- \\ ment Service, Department of Veterans Affairs (VA) Puget Sound Health Care System, Seattle, WA; ${ }^{3}$ Harborview Medi- \\ cal Center, Orthopedic Surgery and Rehabilitation Medicine, Seattle, WA; and Department of Orthopaedic Surgery and \\ Rehabilitation, University of Washington, Seattle, WA; ${ }^{4}$ Department of Physical Medicine and Rehabilitation, Moss- \\ Rehab and Albert Einstein Medical Center, Elkins Park, PA; ${ }^{5}$ Physical Medicine and Rehabilitation Service, VA East- \\ ern Colorado Health Care System, Denver, CO
}

\begin{abstract}
Multiple-limb loss due to war-theater injuries results in a unique group of servicemembers requiring intensive rehabilitation and diverse prosthetic devices. This article compares the Vietnam and the Operation Iraqi Freedom/Operation Enduring Freedom (OIF/OEF) groups with war-theaterassociated multiple-limb loss to document significant changes in health status, prosthetic-device use, and long-term prognosis. During 2007 and 2008, a national survey queried 73 Vietnam veterans and 61 OIF/OEF servicemembers sustaining multiple-limb loss. Average years since limb loss are 39 for Vietnam veterans and 3 for OIF/OEF servicemembers. Selfrated health status was excellent or very good in $38.9 \%$ of the Vietnam group and $60.7 \%$ of the OIF/OEF group $(p=0.01)$. More of the OIF/OEF group than the Vietnam group reported performing high-impact aerobic activities, $18 \%$ versus $3 \%$ ( $p=$ 0.005 ). The OIF/OEF group currently uses more diverse prosthetic-device types than the Vietnam group. Based on Vietnam veterans' 39-year experience, the long-term prognosis for OIF/ OEF servicemembers with multiple-limb loss is an active, fulfilling life. The healthcare team caring for these patients should carefully address proper prosthesis fit and maintenance of good health and function.
\end{abstract}

Key words: combat, multiple-limb loss, OIF/OEF, prosthetic devices, rehabilitation, traumatic limb loss, veterans, Vietnam, wounded servicemembers, wounded warriors.

\section{INTRODUCTION}

Multiple-limb loss due to trauma is uncommon in the civilian community [1-8]. Nothing readily compares with multiple-limb loss due to explosive munitions in the war theater. The proportion of servicemembers with multiple-limb loss increased during all 20th century conflicts [9], as well as during Operation Iraqi Freedom/Operation Enduring Freedom (OIF/OEF). The mortality of those wounded on the battlefield has apparently decreased, thus allowing more persons with multiple-limb loss to survive their injuries [10-11]. Servicemembers who sustained multiple-limb loss during previous conflicts typically required lengthy initial hospitalizations, had difficulty

Abbreviations: $\mathrm{ADL}=$ activities of daily living, $\mathrm{CI}=$ confidence interval, DOD = Department of Defense, NS = not significant, OIF/OEF = Operation Iraqi Freedom/Operation Enduring Freedom, PTSD = posttraumatic stress disorder, SF36 = 36-Item Short Form Health Survey, TBI = traumatic brain injury, VA = Department of Veterans Affairs.

*Address all correspondence to Paul J. Dougherty, MD; Department of Orthopaedic Surgery, University of Michigan, 1500 E Medical Center Dr, Ann Arbor, MI 48109; 734-9365686; fax: 734-647-3449. Email: pauldoug@med.umich.edu DOI:10.1682/JRRD.2009.04.0043 
with prosthetic fit to achieve high levels of function, and had decreased age-associated function compared with those with single-limb loss [2,4].

Although popular literature often portrays servicemembers with multiple-limb loss as persons with insurmountable emotional and physical scars [12], the accuracy of this stereotype can be questioned. Injured servicemembers with multiple-limb loss may improve function and regain their active lifestyle. One such example is Senator Max Cleland from Georgia, who sustained multiple-limb loss during the Vietnam war. Despite his physical limitations, he has a successful career in public service. Information is limited concerning the outcomes for patients who sustained multiple-limb loss due to wartheater injuries, but literature demonstrates successful rehabilitation and initial prosthetic fitting for servicemembers wounded during the Vietnam war [2-4].

Brown reports veterans with multiple lower-limb loss from the Vietnam war obtained a high level of physical function and participated in certain sports activities after wound healing and prosthetic fitting [2]. Dougherty conducted a 28-year follow-up of 23 Vietnam combat veterans who sustained bilateral transfemoral-limb loss due to combat-incurred trauma [4]. The 36-Item Short Form Health Survey (SF-36) scores for these patients compared well with published age- and sex-matched controls in all areas except physical function. He also found that the servicemembers lived relatively normal lives within the context of their physical limitations. Caring for servicemembers with limb loss from the OIF/OEF conflicts has raised a number of questions about the health of servicemembers with multiple-limb loss over their lifetimes. Vietnam veterans with combat-incurred limb loss receive care through the Department of Veterans Affairs (VA); thus, their experience provides an appropriate benchmark to compare with OIF/OEF servicemembers with limb loss. This article compares servicemembers and veterans with traumatic multiple-limb loss between OIF/OEF conflicts and Vietnam war to document differences in health status, prosthetic-device use, and long-term prognosis.

\section{METHODS}

\section{Survey Participants}

Participants in this cross-sectional survey are veterans from the Vietnam war and servicemembers from the OIF/OEF conflicts with at least one major traumatic amputation (excludes digital-only loss) associated with a war-theater injury. After we received institutional and human subjects approvals from the VA and Department of Defense (DOD), Veterans and servicemembers with major limb loss occurring during the Vietnam war (19611973) or OIF/OEF (2000-2008) conflicts were sent an invitational letter to participate in a survey on prosthetic use. A waiver of consent was obtained for survey participants. All servicemembers with major limb loss from OIF/OEF, all Vietnam veterans with unilateral upperlimb loss and multiple-limb loss, and a sample of Vietnam veterans with unilateral lower-limb loss were invited to participate. Survey participants included 298 from the Vietnam war (65\% response rate) and 283 from the OIF/ OEF conflicts (59\% response rate). Enrolled and target populations were similar in the distribution of sex and type of limb loss, although more Vietnam participants with multiple-limb loss were successfully enrolled. Participants took the survey by one of three methods: mail, telephone interview, or Web site. Veterans and servicemembers were surveyed during 2007 to 2008. A detailed description of the study methods is found in article an this issue [13], and a copy of the Survey for Prosthetic Use is in Appendix 1 (available online only). Their article focuses on servicemembers and veterans with multiple-limb loss occurring during the Vietnam war and OIF/ OEF conflicts. Other articles in this issue address unilateral lower-limb loss [14] and unilateral upper-limb loss [15].

\section{Survey Variables}

The survey collected data on basic demographics, current military status, health status, types of comorbidities, war-theater injuries, current functional ability, types of prostheses ever received and currently used, and satisfaction with prostheses.

\section{Basic Demographics and Military and Health Statuses}

Cross-sectional data were collected for current quality of life, health status, comorbidities, social support (married, employment, children, and current military status), ability to perform activities of daily living (ADL), current lowerlimb function, and the effect of prior war-theater injuries on current life. Self-rated health status was assessed with use of a validated tool [16]. Self-rated health status is classified into three groups: (1) excellent to very good, (2) good, and (3) fair to poor. The question on self-reported health status is validated and taken from the SF-36 [17]. 


\section{Comorbidities}

Participants provided information on the presence or absence of 15 types of comorbidities (including arthritis, posttraumatic stress disorder [PTSD], depression, traumatic brain injury [TBI], stroke, diabetes, and migraines) and pain (including phantom pain, residual-limb pain, and chronic back pain). For this study, we created a composite pain score defined as the total number of positive responses to five dichotomized pain questions (phantom, residual limb, back, arthritis, and migraine headache). We also created a composite score of mental health issues, defined as the total number of positive responses to three dichotomized mental health questions (depression, PTSD, and TBI).

\section{War-Theater Injuries}

Participants were asked to report the date and location of all amputations, number of associated surgeries before and after their amputation, level of limb loss, and types of war-theater injuries. The level of amputation was reported as partial foot, ankle, transtibial, knee disarticulation, transfemoral, hip, transpelvic, partial hand, wrist, transradial, elbow disarticulation, transhumeral, shoulder, or forequarter.

Cumulative trauma disorder is from overuse of the nonamputated limb and may include any one of the following for the upper limb: carpal tunnel syndrome, cubital tunnel syndrome, tendonitis, arthritis, stiff or painful joints, or ganglion cysts; or for the lower limb: joint arthritis, stiff joints, heel pain, plantar fasciitis, or heterotopic ossification [18].

\section{Functional Ability}

Functional ability or activity is measured differently for lower and upper limbs. Lower-limb functional ability is assessed with seven graded levels:

- 1 = cannot walk, needs assistance to transfer.

- 2 = cannot walk, does not need help to transfer.

- 3 = household walker.

- 4 = community walker.

- 5 = walks with varying speeds.

- 6 = performs low-impact activities (such as swimming or golf).

- 7 = performs high-impact activities (such as basketball or skiing).

The activity of survey participants with upper-limb loss was based on 23 ADL tasks. These items included performance of tasks related to eating and dressing, com- munity activities, housekeeping, automobile operation, use of tools, and sporting activities. Survey participants with upper-limb loss also indicated how they performed upper-limb tasks as using (1) a prosthesis, (2) a onehanded technique, or (3) the assistance of another person.

\section{Prosthetic Devices}

This descriptive and cross-sectional survey collected data on use of current prosthetic and assistive devices (number and type of devices and daily frequency of use) and satisfaction with current prostheses and services. Survey participants were classified into one of three groups: (1) never received any prostheses, (2) current user (current use of at least one prosthesis), or (3) abandoned (received at least one prosthesis in the past and had currently discontinued use of all prostheses). Nonambulatory survey participants with lower-limb loss are described in another article in this issue [19]. Survey participants were asked which types of prosthetic and assistive devices they might want to try in the next 3 years. Current satisfaction with their prostheses was ranked from 0 (not at all satisfied) to 10 (completely satisfied).

We collected retrospective data on the total number and types of prostheses received for two time periods: during the first 12 months following limb loss and during month 13 to the time of the follow-up. We collected these data because of the first-year variability in rehabilitation as the servicemembers adapted to limb loss and limb volume changes. Data were collected on the number of prostheses that wore out and the average replacement time by type of device. For prostheses that were discontinued because of dissatisfaction, the number and type of device were collected as well as the reasons why participants discontinued the prosthesis. Survey participants self-reported any prosthetic device receipt, regardless whether received through military, VA, or private sources. Survey participants also included prototype prosthetic devices received.

Because of the complexity of prosthetic systems, we summarized prosthetic device types into major groups defined by the degree of technology, device use, and level of limb loss. For limb loss at the knee or above (knee, transfemoral, hip, pelvis), the four groups were-

1. Advanced technology (microprocessor-type device requiring recharging or hybrid [mix of electronic and body-powered parts]).

2. Mechanical (does not require recharging).

3. Specialty (recreational, athletic, or high-impact use).

4. Waterproof (shower or swimming leg). 
For limb loss below the knee (transtibial, ankle, foot), the five groups were-

1. Advanced technology (hybrid [mix of electronic and body-powered parts]).

2. Mechanical (vacuum-assisted system with pump or suction device or types that do not require recharging).

3. Specialty (recreational, athletic, or high-impact use).

4. Waterproof (shower or swimming leg).

5. Cosmetic (nonfunctional limb or foot or ankle only).

For limb loss below the knee (transtibial, ankle, or foot), vacuum-assisted systems were grouped with mechanical devices, because these systems were largely vacuum sockets with mechanical feet. Data for cosmetic devices were also classified according to level of limb loss. For those with foot or ankle-limb loss, the cosmetic device data were included because these devices are used for ambulation and/or balance. For those with higher levels of lower-limb loss, cosmetic device data were excluded because cosmetic devices are not used for ambulation. Some survey participants reported cosmetic coverings for mechanical or microprocessor limbs. Upper-limb prostheses were grouped into three groups: (1) advanced technology (myoelectric, microprocessor, or hybrid), (2) mechanical (body-powered, no batteries needed), and (3) cosmetic (nonfunctional). We collected assistive technology use data (walkers, canes, crutches, car modifications, wheelchairs, terminal upper-limb devices, etc.) for current use and the next predicted use in the next 3 years from survey date.

\section{Statistical Analysis}

This survey is cross-sectional and descriptive. Demographic characteristics, health status, function, prosthetic use, and satisfaction from the Vietnam group were compared with the OIF/OEF group. We analyzed univariate findings using Stata 9.2 (StataCorp; College Station, Texas). For univariate analyses, statistical significance is based on chi-square test (categorical data), Mann-Whitney $U$ test (ordinal data), Student $t$-test (continuous data), and Fisher exact test (if cell sizes 5). The level of significance is a two-sided $p \leq 0.05$.

\section{RESULTS}

\section{Vietnam and OIF/OEF Group Comparison}

This article includes only those with multiple-limb loss. Seventy-three Vietnam combat veterans sustained multiple-limb loss (153 limbs), and sixty-one OIF/OEF servicemembers sustained multiple-limb loss (129 limbs). Average follow-up of the veterans from the time of injury was $38.8 \pm 3.6$ years for the Vietnam group and $3.0 \pm$ 1.2 years for the OIF/OEF group. (Values are expressed as mean \pm standard deviations throughout article, unless otherwise specified.)

The anatomic distribution of the level of limb loss was similar for both the Vietnam and OIF/OEF groups (Figure 1). Detailed descriptions of the types of multiplelimb loss are given in Table 1; 44 different combinations are given. Bilateral lower-limb loss was frequent in both Vietnam and OIF/OEF groups (68\% and 69\%, respectively). Bilateral upper-limb loss was found in 8 percent of Vietnam group and 11 percent of OIF/OEF group. Loss of three limbs is infrequent for both Vietnam and OIF/OEF groups (10\% and $11 \%$ ) in comparison to those with bilateral lower-limb loss.

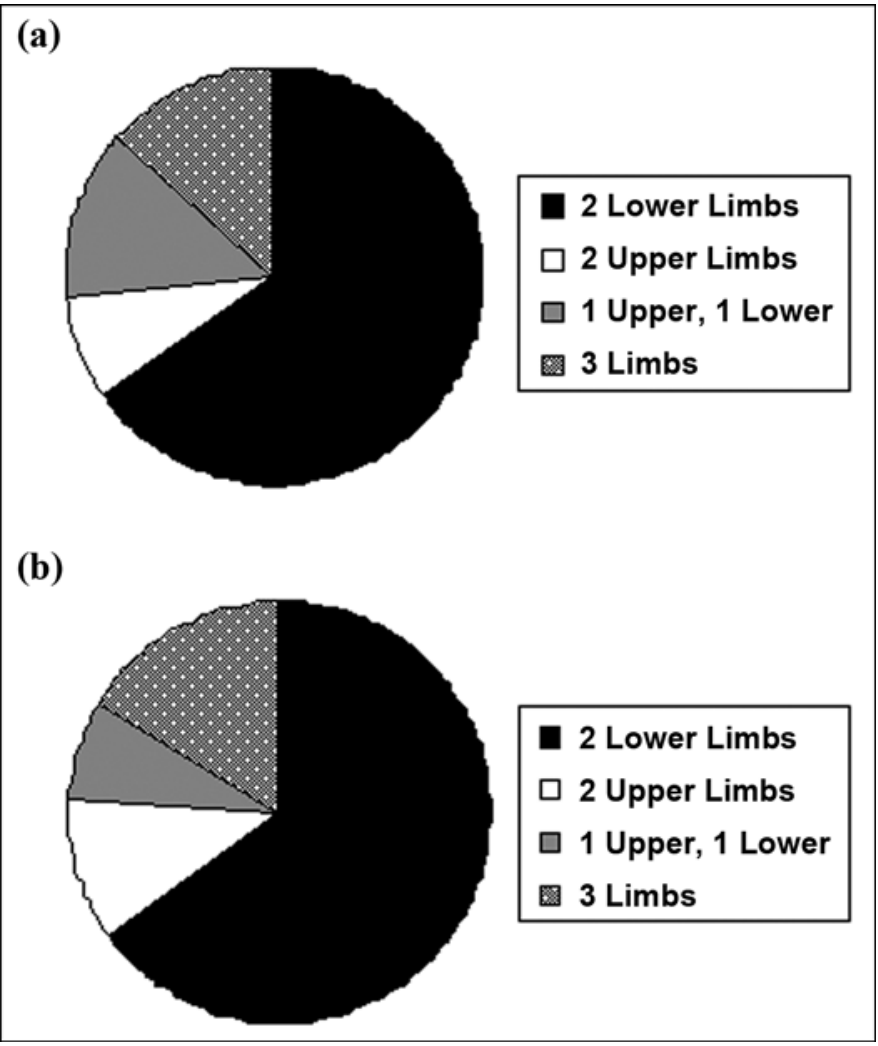

Figure 1.

Distribution of types of multiple-limb loss in (a) Vietnam (153 total limbs) and (b) OIF/OEF (129 total limbs) groups. 
Table 1.

Types of multiple-limb loss in veterans and servicemembers from Vietnam war $(n=73)$ and OIF/OEF $(n=61)$ conflict groups.

\begin{tabular}{|c|c|c|}
\hline Levels of Amputation & $\begin{array}{l}\text { Vietnam } \\
\text { No. (\%) }\end{array}$ & $\begin{array}{c}\text { OIF/OEF } \\
\text { No. (\%) }\end{array}$ \\
\hline \multicolumn{3}{|l|}{ Two Lower Limbs } \\
\hline Transfemoral-Transfemoral & $23(31.5)$ & $10(16.4)$ \\
\hline Transtibial-Transfemoral & $13(17.8)$ & $11(18.0)$ \\
\hline Transtibial-Transtibial & $5(6.9)$ & 8 (13.1) \\
\hline Transtibial-Knee & $3(4.1)$ & $4(6.6)$ \\
\hline Knee-Knee & $2(2.7)$ & $1(1.6)$ \\
\hline Transtibial-Ankle & $2(2.7)$ & $0(-)$ \\
\hline Ankle-Knee & $1(1.4)$ & $0(-)$ \\
\hline Transfemoral-Knee & $1(1.4)$ & $2(3.3)$ \\
\hline Transfemoral-Ankle & $0(-)$ & $1(1.6)$ \\
\hline Transtibial-Hip & $0(-)$ & $1(1.6)$ \\
\hline Transtibial-Foot & $0(-)$ & $3(4.9)$ \\
\hline Transfemoral-Pelvis & $0(-)$ & $1(1.6)$ \\
\hline \multicolumn{3}{|l|}{ Two Upper Limbs } \\
\hline Transhumeral-Chest & $1(1.4)$ & $0(-)$ \\
\hline Transradial-Transradial & $1(1.4)$ & $2(3.3)$ \\
\hline Transradial-Elbow & $1(1.4)$ & $0(-)$ \\
\hline Hand-Hand & $1(1.4)$ & $0(-)$ \\
\hline Shoulder-Shoulder & $1(1.4)$ & $0(-)$ \\
\hline Transradial-Hand & $0(-)$ & $2(3.3)$ \\
\hline Hand-Elbow & $0(-)$ & $1(1.6)$ \\
\hline Transradial-Wrist & $0(-)$ & $1(1.6)$ \\
\hline \multicolumn{3}{|l|}{ One Upper and One Lower Limb } \\
\hline Transfemoral-Transhumeral & $2(2.7)$ & $1(1.6)$ \\
\hline Transfemoral-Shoulder & $2(2.7)$ & $1(1.6)$ \\
\hline Transfemoral-Hand & $2(2.7)$ & $0(-)$ \\
\hline Transfemoral-Elbow & $1(1.4)$ & $0(-)$ \\
\hline Transtibial-Hand & $1(1.4)$ & $0(-)$ \\
\hline Transtibial-Transhumeral & $1(1.4)$ & $0(-)$ \\
\hline Hand-Transhumeral & $1(1.4)$ & $1(1.6)$ \\
\hline Hip-Transhumeral & $1(1.4)$ & $0(-)$ \\
\hline Transfemoral-Transradial & $0(-)$ & $1(1.6)$ \\
\hline Transfemoral-Wrist & $0(-)$ & $1(1.6)$ \\
\hline Knee-Transhumeral & $0(-)$ & $1(1.6)$ \\
\hline \multicolumn{3}{|l|}{ Three Limbs } \\
\hline Transfemoral-Transfemoral-Hand & $1(1.4)$ & $1(1.6)$ \\
\hline Transfemoral-Hip-Transradial & $1(1.4)$ & $0(-)$ \\
\hline Transfemoral-Hip-Hand & $1(1.4)$ & $0(-)$ \\
\hline Transfemoral-Transhumeral-Transhumeral & $1(1.4)$ & $0(-)$ \\
\hline Transtibial-Transtibial-Transradial & $1(1.4)$ & $0(-)$ \\
\hline Knee-Transfemoral-Transradial & $1(1.4)$ & $0(-)$ \\
\hline Knee-Transradial-Elbow & $1(1.4)$ & $0(-)$ \\
\hline Transfemoral-Transfemoral-Transradial & $0(-)$ & $1(1.6)$ \\
\hline Transtibial-Transtibial-Hand & $0(-)$ & $1(1.6)$ \\
\hline Transtibial-Hand-Transradial & $0(-)$ & $1(1.6)$ \\
\hline Transtibial-Hand-Hand & $0(-)$ & $1(1.6)$ \\
\hline Foot-Transtibial-Hand & $0(-)$ & $1(1.6)$ \\
\hline Knee-Knee-Hand & $0(-)$ & $1(1.6)$ \\
\hline Total Persons & 73 & 61 \\
\hline
\end{tabular}

This heterogenous distribution shows the most common multiple-limb-loss levels for the Vietnam and OIF/ OEF groups, respectively, are bilateral transfemoral (31.5\% and $16.4 \%)$, transtibial/transfemoral (17.8\% and $18 \%)$, and bilateral transtibial (6.9\% and 13.1\%). The diverse combinations of groups of limb loss were categorized into 12 limb-loss types and are presented in Tables 1 through 7.

Demographic data show some differences between the Vietnam group and the OIF/OEF group. The average age at follow-up was $60.7 \pm 2.6$ years for the Vietnam group and $28.0 \pm 4.6$ years for the OIF/OEF group. All of the Vietnam group and 95 percent of the OIF/OEF group were male. In the Vietnam group, 76 percent reported being married or living together and 85 percent reported having children. Of the OIF/OEF group, 61 percent reported being married or living together and 46 percent reported having children. None of the survey participants from the Vietnam group was on Active Duty. In the OIF/ OEF group, 23 percent indicated that they were on Active Duty and 14.8 percent reported they were still in rehabilitation. Of the Vietnam veterans with multiple-limb loss, 76 percent reported current employment. In the OIF/OEF group, 53 percent reported current employment and an additional 15 percent reported being in school. No significant differences were reported by the type of limb-loss group for demographic or lifestyle factors between the Vietnam and the OIF/OEF groups (data not shown) [13].

The average number of surgeries following the initial amputation for all survey participants with multiple-limb loss is $2.5 \pm 4.3$ for the Vietnam group and $5.5 \pm 6.1$ for the OIF/OEF group $(p=0.001)$. Following bilateral transtibial- and/or transfemoral-limb loss, the average number of additional surgeries to the limbs was $3.3 \pm 3.5$ and $16.7 \pm 14.7$ for the Vietnam and OIF/OEF groups, respectively, $p=0.004$ (data not shown).

\section{Survey Variables}

\section{Comorbidities}

Significant differences were found in the types of comorbidities between the Vietnam and OIF/OEF groups (Table 2). Overall, chronic back pain prevalence was similar between the Vietnam and OIF/OEF groups (19\% and 21\%, respectively); however, important differences emerged by level of limb loss. For the Vietnam and OIF/ OEF groups, respectively, chronic back pain was less frequent for those with bilateral transfemoral-limb loss (8\% and $0 \%$ ) and higher in those with bilateral transtibiallimb loss (40\% and 38\%). No significant difference was 
JRRD, Volume 47, Number 4, 2010

Table 2.

Current health issues for veterans and servicemembers with multiple-limb loss from Vietnam and OIF/OEF groups.

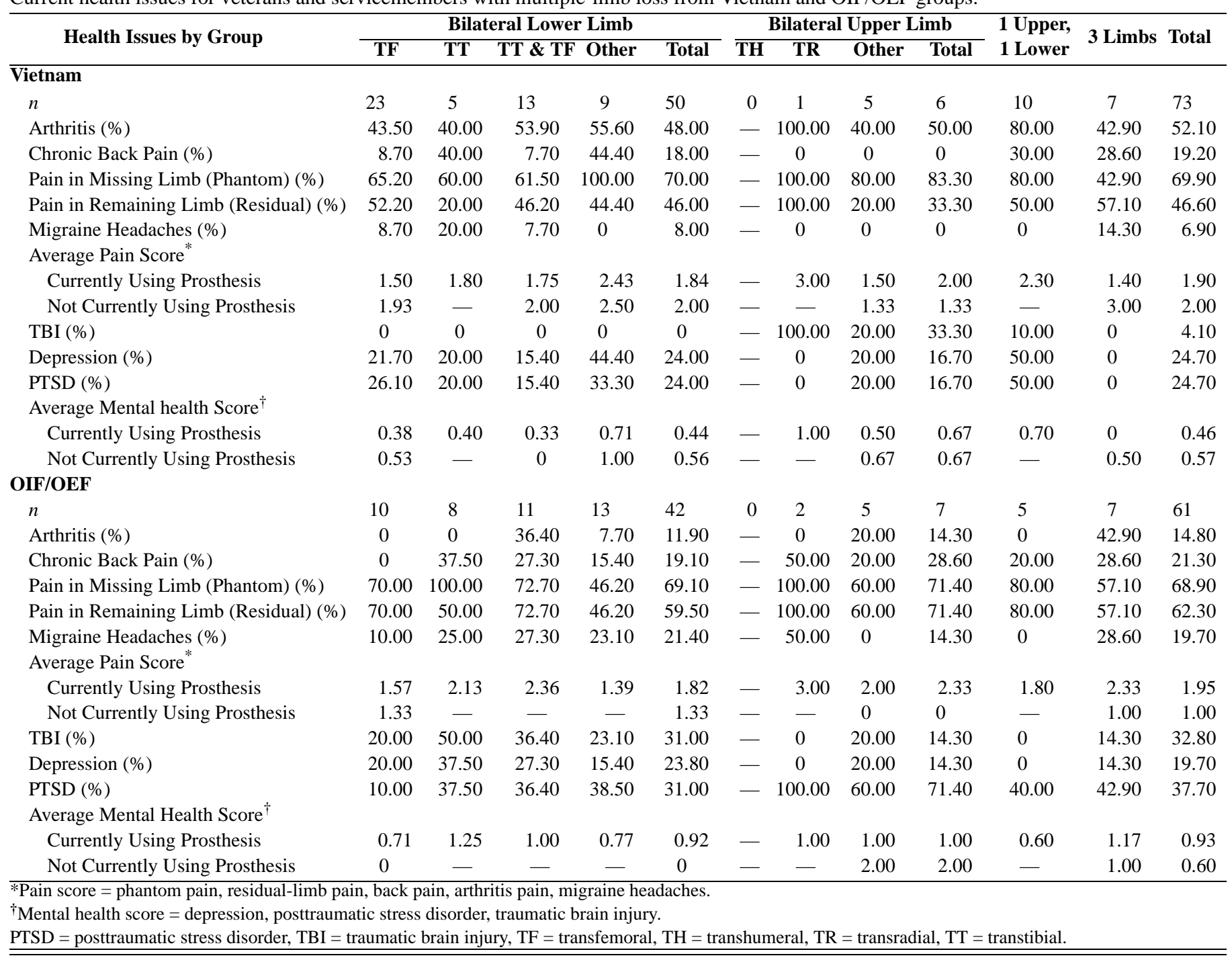

found between the Vietnam and OIF/OEF groups regarding phantom pain (69.9\% and $68.9 \%$, respectively). However, a lower prevalence of residual-limb pain was found between the groups, 46.6 percent (Vietnam) versus 62.3 percent $(\mathrm{OIF} / \mathrm{OEF})(p=0.07)$. Migraine headaches occurred more often in the OIF/OEF group than the Vietnam group ( $20 \%$ and $7 \%$, respectively, $p=0.03$ ). TBI prevalence increased significantly between the Vietnam (4.1\%) and OIF/OEF groups $(19.7 \%, p<0.01)$. Depression, PTSD, mental health, and pain scores were not significantly different by conflict group or by type of limbloss group (Table 2). Pain or mental health conditions were not significantly different between those who did and did not use prostheses. Nor was the development of cumulative trauma disorder significantly higher for upper limbs (30\% in Vietnam and 10\% in OIF/OEF) than lower limbs (10\% and $4 \%$, respectively) (data not shown).

Five other age-related comorbidities were reported more frequently in the Vietnam group than the OIF/OEF group: arthritis (52\% and 15\%, respectively, $p<0.01$ ), difficulties with vision (38.4\% and $16.4 \%$, respectively, $p=0.005)$, heart attacks ( $16.4 \%$ and $0 \%$, respectively, $p=$ 0.001 ), diabetes ( $15.1 \%$ and $0 \%$, respectively, $p=0.002$ ), and kidney disease (6.8\% and $0 \%$, respectively, $p=0.04$ ). Other comorbidities were infrequently reported in both groups: stroke, cancer, chronic lung disease, asthma, pneumonia, gastrointestinal disorders, and peripheral arterial disease. 


\section{War-Theater Injuries}

Other war-theater injuries in addition to limb loss are shown in Table 3. A trend for fewer injuries has occurred to a nonamputated limb in the Vietnam group (26\%) compared with the OIF/OEF group $(41 \%, p=0.07)$. Overall, 22 percent of the Vietnam group reported head injuries versus 34 percent of the OIF/OEF group with multiple-limb loss (not significant [NS]). Head injuries, eye injuries, and hearing loss are more commonly reported in participants with bilateral multiple upperlimb injuries than in those with bilateral lower-limb injuries (Table 3).

\section{Self-Reported Health}

Of the veterans in the Vietnam group, 38.9 percent reported their health as "excellent to very good" compared with 60.7 percent in the OIF/OEF group $(p=0.01)$. Self-rated health status varied by the type of limb loss (Table 4). Among those with bilateral transfemoral-limb loss, 41 percent of the Vietnam group and 80 percent of the OIF/OEF group rated their health status as excellent to very good $(p=0.04)$. The limb-loss pattern associated most often with fair to poor health includes the loss of one upper and one lower limb. Currently, only 21 percent of the Vietnam group reported that they needed assistance to complete daily tasks compared with 32 percent of the OIF/OEF group (NS). No significant differences were found for participants who reported needing assistance by type of limb loss for either conflict (Table 4).

\section{Functional Ability}

Upper-limb function for those with upper-limb loss is described in Table 5. Comparing the Vietnam and OIF/ OEF groups, 26 and 37 percent, respectively, perform the majority of ADL tasks with a prosthesis; 61 and 58 percent, respectively, use a one-hand adapted technique; and 13 and 5 percent, respectively, require the assistance of another person (NS). No significant differences were found in how these tasks are performed by type of limbloss group between the two conflict groups (Table 5).

Lower-limb functional ability is measured in seven levels, as shown in Table 5. Significantly more of the Vietnam group (33\%) cannot walk compared with the OIF/OEF group $(6 \%, p<0.001)$. Significantly more of the OIF/OEF group reported that they perform low- to highimpact activities (39\%) compared with the Vietnam group $(14 \%, p=0.001)$. The OIF/OEF group with bilateral lower-limb loss reported significantly greater frequency (17\%) of performing high-impact activities, such as basketball or skiing, than the Vietnam group $(2 \%)(p<0.01)$.

Table 3.

Other war-theater injuries in veterans and servicemembers with multiple-limb loss from Vietnam and OIF/OEF groups.

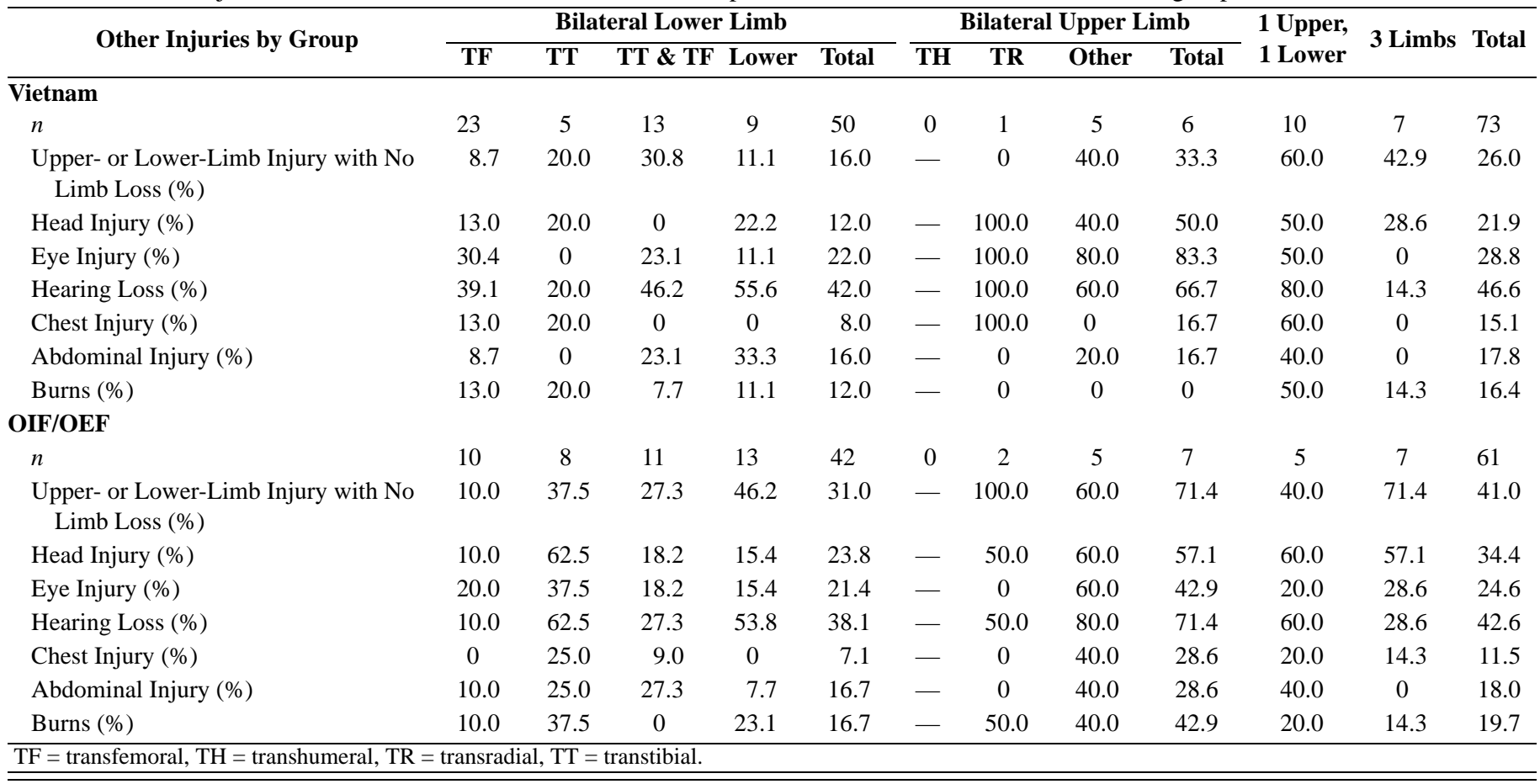


JRRD, Volume 47, Number 4, 2010

Table 4.

Self-reported health and need for assistance from others in veterans and servicemembers with multiple-limb loss from Vietnam and OIF/OEF groups.

\begin{tabular}{|c|c|c|c|c|c|c|c|c|c|c|c|c|}
\hline \multirow{2}{*}{ Self-Reported Health by Group } & \multicolumn{5}{|c|}{ Bilateral Lower Limb } & \multicolumn{4}{|c|}{ Bilateral Upper Limb } & \multirow{2}{*}{$\begin{array}{l}1 \text { Upper, } \\
1 \text { Lower }\end{array}$} & \multirow{2}{*}{3 Limbs } & \multirow{2}{*}{ Total } \\
\hline & TF & TT & TT \& TF & Other & Total & TH & TR & Other & Total & & & \\
\hline \multicolumn{13}{|l|}{ Vietnam } \\
\hline$n$ & 23 & 5 & 13 & 9 & 50 & 0 & 1 & 5 & 6 & 10 & 7 & 73 \\
\hline Excellent/Very Good & 40.9 & 0 & 46.2 & 22.2 & 34.7 & - & 100.0 & 60.0 & 66.7 & 30.0 & 57.1 & 38.9 \\
\hline Good & 50.0 & 60.0 & 38.5 & 55.6 & 49.0 & - & 0 & 40.0 & 33.0 & 20.0 & 42.9 & 43.1 \\
\hline Fair/Poor & 9.1 & 40.0 & 15.4 & 22.2 & 16.3 & - & 0 & 0 & 0 & 50.0 & 0 & 18.1 \\
\hline \multicolumn{13}{|l|}{ OIF/OEF } \\
\hline$n$ & 10 & 8 & 11 & 13 & 42 & 0 & 2 & 5 & 7 & 5 & 7 & 61 \\
\hline \multicolumn{13}{|l|}{ Self-Reported Health (\%) } \\
\hline Excellent/Very Good & 80.0 & 62.5 & 54.6 & 69.2 & 66.7 & - & 0 & 80.0 & 57.1 & 60.0 & 28.6 & 60.7 \\
\hline Good & 20.0 & 25.0 & 27.3 & 30.8 & 26.2 & - & 100.0 & 0 & 28.6 & 20.0 & 57.1 & 29.5 \\
\hline
\end{tabular}

Table 5.

Upper- and lower-limb functional ability in veterans and servicemembers with multiple-limb loss from Vietnam and OIF/OEF groups.

\begin{tabular}{|c|c|c|c|c|c|c|c|c|c|c|c|c|}
\hline \multirow{2}{*}{ Functional Ability by Group } & \multicolumn{5}{|c|}{ Bilateral Lower Limb } & \multicolumn{4}{|c|}{ Bilateral Upper Limb } & \multirow{2}{*}{$\begin{array}{l}1 \text { Upper, } \\
1 \text { Lower }\end{array}$} & \multirow{2}{*}{3 Limbs } & \multirow{2}{*}{ Total } \\
\hline & TF & TT & TT \& TF & Other & Total & TH & TH & Other & Total & & & \\
\hline \multicolumn{13}{|l|}{ Vietnam } \\
\hline$n$ & 23 & 5 & 13 & 9 & 50 & 0 & 1 & 5 & 6 & 10 & 7 & 73 \\
\hline \multicolumn{13}{|l|}{ Lower-Limb Function Level (\%) } \\
\hline 1 = Need Transfer Help, Cannot Walk & 4.4 & 0 & 0 & 11.1 & 4.0 & - & - & - & - & 10.0 & 14.3 & 6.0 \\
\hline 2 = Do Not Need Transfer Help, Cannot Walk & 60.9 & 0 & 0 & 11.1 & 30.0 & - & - & - & - & 0 & 42.9 & 26.9 \\
\hline 3 = Household Walker & 8.7 & 20.0 & 7.7 & 0 & 8.0 & - & - & - & - & 10.0 & 0 & 7.5 \\
\hline 4 = Community Walker & 4.4 & 0 & 46.2 & 22.2 & 18.0 & - & - & - & - & 30.0 & 0 & 17.9 \\
\hline 5 = Can Walk Varying Speeds & 8.7 & 80.0 & 30.8 & 44.4 & 28.0 & - & - & - & - & 30.0 & 28.6 & 28.4 \\
\hline 6 = Low-Impact Activities & 8.7 & 0 & 15.4 & 11.1 & 10.0 & - & - & - & - & 20.0 & 0 & 10.5 \\
\hline 7 = High-Impact Activities & 4.4 & 0 & 0 & 0 & 2.0 & - & - & - & - & 0 & 14.3 & 3.0 \\
\hline \multicolumn{13}{|l|}{ Upper-Limb Function (\%) } \\
\hline Do Majority of Tasks with Prostheses & - & - & - & - & - & - & 0 & 20.0 & 16.7 & 20.0 & 42.9 & 26.1 \\
\hline Do Majority of Tasks One-Handed & - & - & - & - & - & - & 0 & 60.0 & 50.0 & 70.0 & 57.1 & 60.9 \\
\hline Do Majority of Tasks Needing Assistance & - & - & - & - & - & - & 100.0 & 20.0 & 33.3 & 10.0 & 0 & 13.0 \\
\hline \multicolumn{13}{|l|}{ OIF/OEF } \\
\hline$n$ & 10 & 8 & 11 & 13 & 42 & 0 & 2 & 5 & 7 & 5 & 7 & 61 \\
\hline \multicolumn{13}{|l|}{ Lower-Limb Function Level (\%) } \\
\hline 1 = Need Transfer Help, Cannot Walk & 0 & 0 & 0 & 0 & 0 & - & - & - & - & 0 & 0 & 0 \\
\hline 2 = Do Not Need Transfer Help, Cannot Walk & 30.0 & 0 & 0 & 0 & 7.1 & - & - & - & - & 0 & 0 & 5.6 \\
\hline $3=$ Household Walker & 20.0 & 0 & 9.1 & 15.4 & 11.9 & - & - & - & - & 0 & 28.6 & 13.0 \\
\hline 4 = Community Walker & 30.0 & 12.5 & 27.3 & 15.4 & 21.4 & - & - & - & - & 20.0 & 28.6 & 22.2 \\
\hline 5 = Can Walk Varying Speeds & 10.0 & 37.5 & 18.2 & 38.5 & 26.2 & - & - & - & - & 0 & 0 & 20.4 \\
\hline $6=$ Low-Impact Activities & 0 & 50.0 & 9.1 & 15.4 & 16.7 & - & - & - & - & 40.0 & 28.6 & 20.4 \\
\hline 7 = High-Impact Activities & 10.0 & 0 & 36.4 & 15.4 & 16.7 & - & - & - & - & 40.0 & 14.3 & 18.5 \\
\hline \multicolumn{13}{|l|}{ Upper-Limb Function (\%) } \\
\hline Do Majority of Tasks with Prostheses (\%) & - & - & - & - & - & - & 100.0 & 60.0 & 71.4 & 20.0 & 14.3 & 36.9 \\
\hline Do Majority of Tasks One-Handed & - & - & - & - & - & - & 0 & 40.0 & 28.6 & 80.0 & 71.4 & 57.9 \\
\hline Do Majority of Tasks Needing Assistance (\%) & - & - & - & - & - & - & 0 & 0 & 0 & 0 & 14.3 & 5.3 \\
\hline
\end{tabular}


Table 6.

Prosthetic use in veterans and servicemembers with multiple-limb loss from Vietnam and OIF/OEF groups.

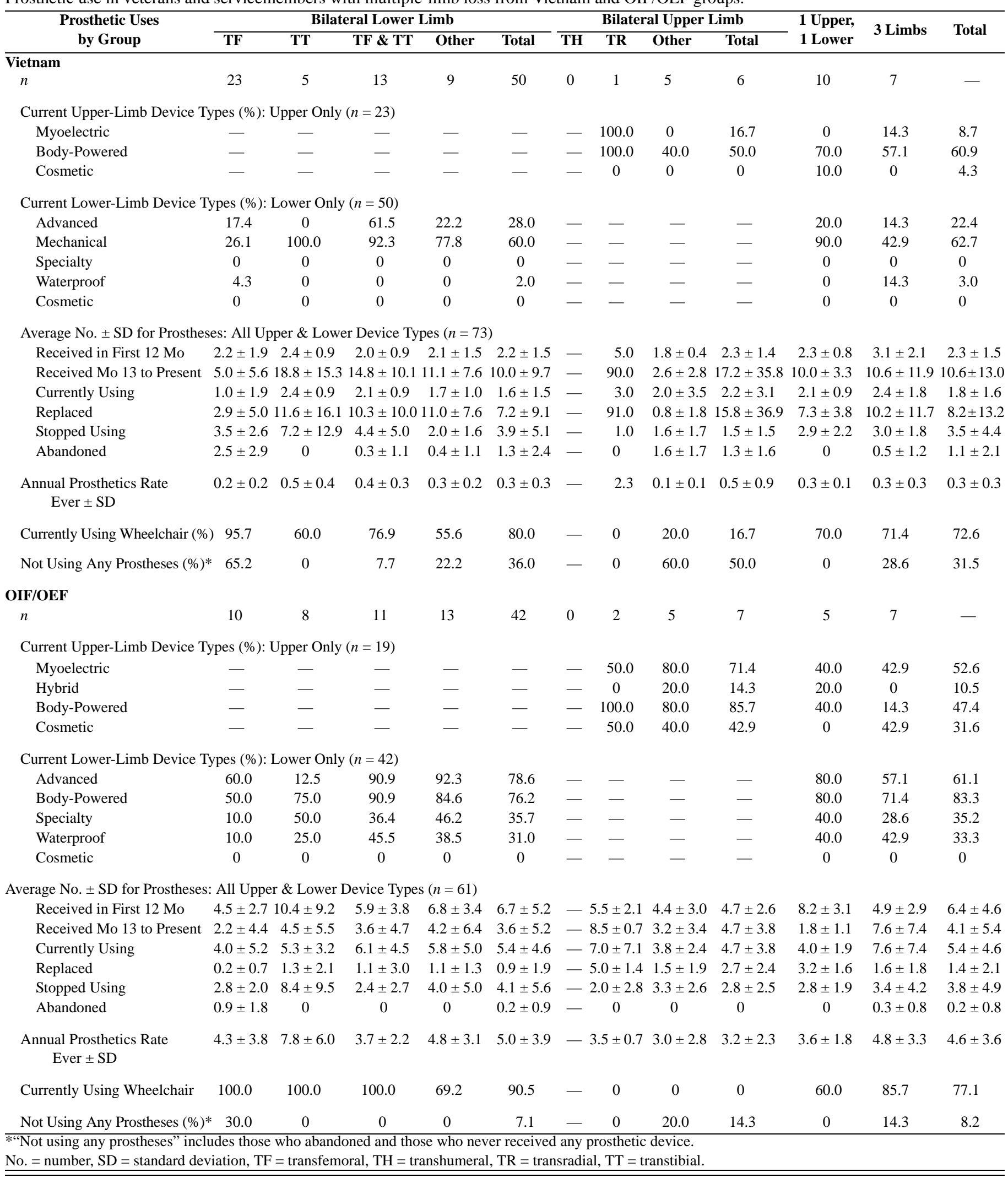


JRRD, Volume 47, Number 4, 2010

Table 7.

Issues for those who currently use prostheses by limb-loss level in veterans and servicemembers with multiple-limb loss from Vietnam and OIF/OEF groups.

\begin{tabular}{|c|c|c|c|c|c|c|c|c|c|c|c|c|}
\hline \multirow{2}{*}{ Prosthetic Issues by Group } & \multicolumn{5}{|c|}{ Bilateral Lower Limb } & \multicolumn{4}{|c|}{ Bilateral Upper Limb } & \multirow{2}{*}{$\begin{array}{l}1 \text { Upper, } \\
1 \text { Lower }\end{array}$} & \multirow{2}{*}{3 Limbs } & \multirow{2}{*}{ Total } \\
\hline & TF & TT & TT \& TF & Other & Total & $\overline{\mathbf{T H}}$ & TR & Other & Total & & & \\
\hline \multicolumn{13}{|l|}{$\overline{\text { Vietnam }}$} \\
\hline$n$ & 23 & 5 & 13 & 9 & 50 & 0 & 1 & 5 & 6 & 10 & 7 & 73 \\
\hline No. Currently Using Prostheses & 8 & 5 & 12 & 7 & 32 & 0 & 1 & 2 & 3 & 10 & 5 & 50 \\
\hline $\begin{array}{l}\text { Average No. } \pm \text { SD for Prosthesis Satis- } \\
\text { faction } 0-10\end{array}$ & $7.2 \pm 2.6$ & $5.8 \pm 3.5$ & $6.5 \pm 3.1$ & $7.5 \pm 1.4$ & $6.8 \pm 2.7$ & - & 7.0 & $7.5 \pm 0.7$ & $7.3 \pm 0.6$ & $5.6 \pm 1.9$ & $8.0 \pm 2.7$ & $6.7 \pm 2.5$ \\
\hline \multicolumn{13}{|c|}{ Prosthetic Satisfaction (\% who feel this way) } \\
\hline My prosthesis fits well. & 88 & 80 & 75 & 100 & 84 & - & 100 & 50 & 67 & 89 & 100 & 86 \\
\hline My prosthesis is pain-free to wear. & 63 & 50 & 63 & 71 & 63 & - & 50 & 50 & 50 & 44 & 80 & 60 \\
\hline I am bothered with skin problems. & 38 & 60 & 33 & 71 & 47 & - & 100 & 50 & 67 & 50 & 30 & 47 \\
\hline I am satisfied with my prosthesis. & 100 & 80 & 75 & 86 & 84 & - & 100 & 100 & 100 & 72 & 100 & 85 \\
\hline \multicolumn{13}{|l|}{ Socket Satisfaction (\% who feel this way) } \\
\hline $\begin{array}{l}\text { I am happy with the comfort and } \\
\text { fit of my socket. }\end{array}$ & 75 & 80 & 75 & 64 & 73 & - & 100 & 100 & 100 & 72 & 100 & 78 \\
\hline $\begin{array}{l}\text { I cannot wear my prosthesis } \\
\text { because my socket fits poorly. }\end{array}$ & 13 & 20 & 17 & 14 & 16 & - & 0 & 0 & 0 & 6 & 7 & 12 \\
\hline \multicolumn{13}{|l|}{ OIF/OEF } \\
\hline$n$ & 10 & 8 & 11 & 13 & 42 & 0 & 2 & 5 & 7 & 5 & 7 & \\
\hline No. Currently Using Prostheses & 7 & 8 & 11 & 13 & 39 & 0 & 2 & 4 & 6 & 5 & 6 & 56 \\
\hline $\begin{array}{l}\text { Average No. } \pm \text { SD for Prosthesis Satis- } \\
\text { faction } 0-10\end{array}$ & $7.5 \pm 1.9$ & $8.6 \pm 0.9$ & $7.8 \pm 3.0$ & $8.3 \pm 1.3$ & $8.1 \pm 1.9$ & - & $7.0 \pm 1.4$ & $6.3 \pm 1.0$ & $6.5 \pm 1.0$ & $8.0 \pm 1.0$ & $8.1 \pm 1.4$ & $7.9 \pm 1.8$ \\
\hline \multicolumn{13}{|c|}{ Prosthetic Satisfaction (\% who feel this way) } \\
\hline My prosthesis fits well. & 86 & 100 & 77 & 100 & 91 & - & 100 & 75 & 83 & 80 & 83 & 88 \\
\hline My prosthesis is pain-free to wear. & 43 & 75 & 46 & 62 & 56 & - & 0 & 50 & 33 & 100 & 56 & 58 \\
\hline I am bothered with skin problems. & 29 & 68 & 36 & 54 & 47 & - & 50 & 25 & 33 & 20 & 67 & 46 \\
\hline $\begin{array}{l}\text { I am satisfied with my prosthesis. } \\
\text { Socket Satisfaction }\end{array}$ & 86 & 100 & 82 & 92 & 90 & - & 100 & 25 & 50 & 60 & 75 & 81 \\
\hline $\begin{array}{l}\text { I am happy with the comfort } \\
\text { and fit of my socket. }\end{array}$ & 100 & 100 & 68 & 89 & 87 & - & 100 & 75 & 83 & 80 & 73 & 85 \\
\hline $\begin{array}{l}\text { I cannot wear my prosthesis } \\
\text { because my socket fits poorly. }\end{array}$ & 14 & 0 & 18 & 8 & 10 & - & 0 & 25 & 17 & 0 & 7 & 10 \\
\hline
\end{tabular}

\section{Prosthetic Devices}

Ever Received. The Vietnam group with multiplelimb loss received an average of 1.0 prosthetic device every 3 years compared with the OIF/OEF group who, to date, received an average of 4.6 devices a year $(p<$ 0.001 ), resulting in a 15 times higher annual receipt rate of prosthetic devices than the Vietnam veterans (Table 6). In the Vietnam group, the one veteran with bilateral transradial-limb loss received an average 2.3 upper-limb prostheses a year to maintain his active life, operating a farm and teaching Special Olympics children to ski. The average number of prostheses received by the OIF/OEF bilateral upper-limb-loss group (mean 3.2 a year) was slightly higher than the Vietnam group. In the Vietnam group with lower-limb loss, those with bilateral transtibial loss received the highest average of 0.5 lower-limb prostheses a year, as well as the OIF/OEF group who received an average of 7.8 a year. The average number of prostheses received varied by type of limb loss and conflict group (Table 6).

Currently Used. Among those with multiple-limb loss, 68 percent of the Vietnam group at the time used at least one prosthetic device, while 92 percent of the OIF/ OEF group used at least one prosthesis, $p<0.001$ (Table 6). The OIF/OEF participants used an average $5.4 \pm 4.6$ different prostheses each year, whereas Vietnam veterans currently only used an average of $1.8 \pm 1.6$ prostheses a year. Survey participants with multiple-limb loss who currently did and did not use a prosthesis are shown in Figure 2. In the Vietnam group, the highest frequency of prostheticdevice use was for limb loss involving one upper and one lower limb. Among the OIF/OEF group, the highest frequency of device used was by those with bilateral lowerlimb loss. For each of the other multiple-limb-loss combinations, at least one-half used one or more prostheses. 
Upper-limb prosthetic devices used at the time by the Vietnam and OIF/OEF veterans with multiple-limb loss are myoelectric (8.7\% and 52.6\%, respectively), bodypowered $(60.9 \%$ and $47.4 \%$, respectively), cosmetic (4.3\% and 31.6\%, respectively), and hybrid limbs, which are used by 10.5 percent of the OIF/OEF group. In the Vietnam and OIF/OEF veterans with multiple-limb loss who used lower-limb prosthetic devices, 22.4 and 61.1 percent, respectively, used advanced (microprocessor) limbs; 62.7 and 83.7 percent, mechanical limbs; and 3.0 and 33.3 percent, waterproof limbs. In addition, 35.2 percent of veterans from the OIF/OEF group used a specialty prosthetic device. A description of the types of prostheses used, replaced, and rejected at the time is shown in Table 6 by the types of limb loss.

\section{Abandonment}

Some participants reported that they were not satisfied with their prosthetic device and abandoned it. The survey asked participants the reasons for satisfaction and dissatisfaction with their current prostheses (Table 7). The overall satisfaction with current prostheses is ranked from 0 (low) to 10 (high). The Vietnam group was significantly less satisfied (mean of 6.7) than the OIF/OEF group (mean of 7.9, $p<0.001$ ). Although both Vietnam and OIF/ OEF groups reported that their prostheses fit well (86\% and $88 \%$, respectively), only 60 percent of the Vietnam

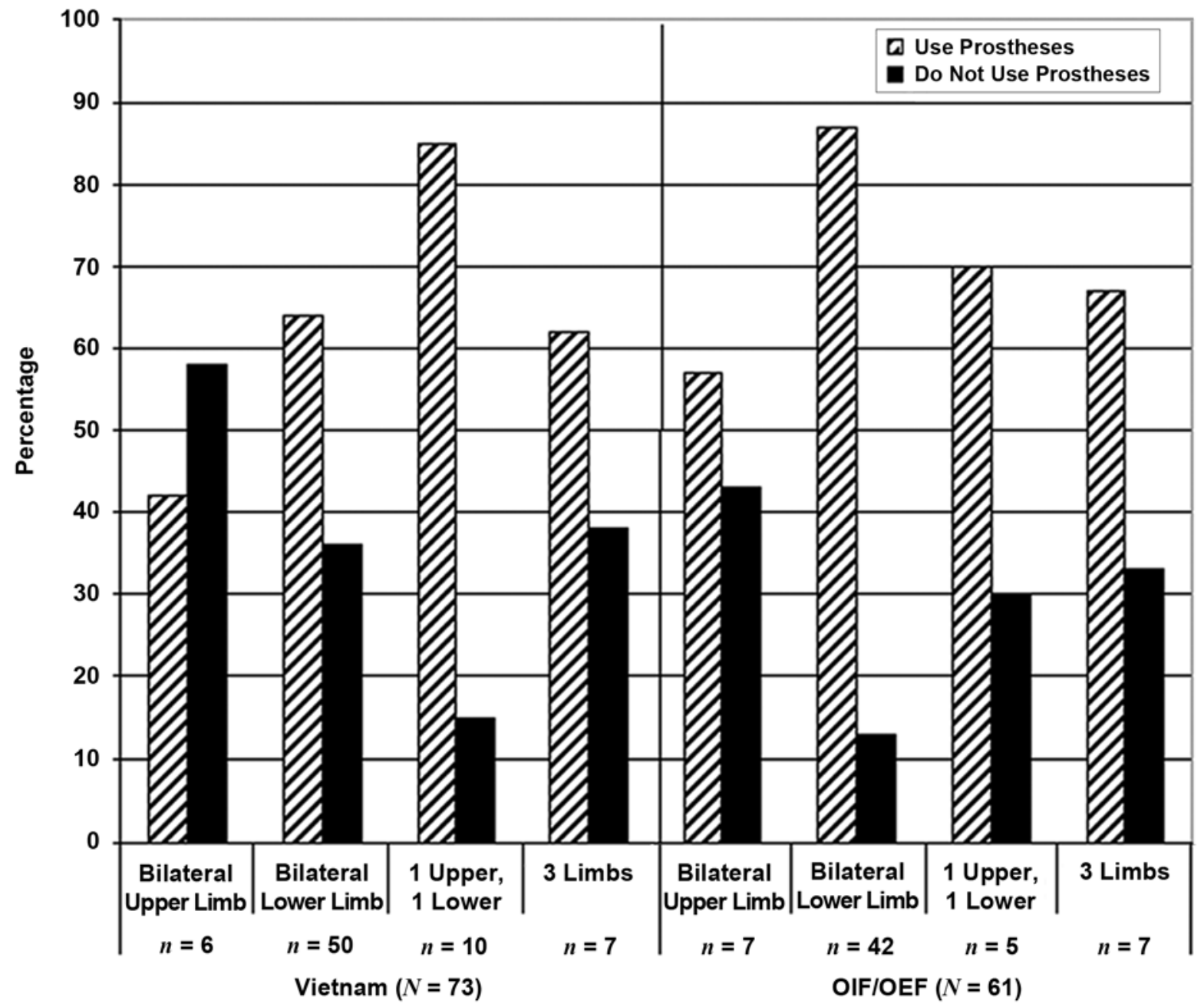

Figure 2.

Prostheses use in servicemembers and veterans with multiple-limb loss from Vietnam and OIF/OEF groups. 
group and 58 percent of the OIF/OEF reported that their prostheses were pain-free to wear. Painful fit was more frequently reported for upper-limb loss in the Vietnam group and for bilateral lower-limb loss in the OIF/OEF group (Table 7). Both groups were generally satisfied with their prostheses and their socket fit.

In the multiple-limb-loss groups, 73 percent from Vietnam group and 77 percent from OIF/OEF group currently use a wheelchair to aid mobility (Table 6). Overall, 29.0 percent of the Vietnam group and 5.1 percent of the OIF/OEF group with multiple-limb loss abandoned the use of all prostheses ( $p=0.001$ ) (data not shown). Abandonment by type of limb loss is shown in Table 6, with no significant differences in the frequency of abandonment by limb-loss level. Abandonment of prostheses by those with bilateral transfemoral-limb loss may have been gradual since the time of limb loss, given the physical effort needed to ambulate with bilateral prostheses. As these individuals age, using a wheelchair as their primary means of ambulation may become more practical. Of those with bilateral transfemoral-limb loss, the OIF/OEF group abandoned significantly more advanced microprocessor prostheses (3.0 \pm 1.1 vs $0.1 \pm 0.5, p<0.001)$ compared with the Vietnam group. No other significant differences were found in the types of prostheses abandoned between the two groups.

\section{DISCUSSION}

Our study showed survey participants with wartheater-associated multiple-limb loss are a heterogeneous group regarding to level of limb loss, types of war-theater injuries, and numbers of surgeries. In our survey, the most common multiple-limb-loss groups are those with bilateral transfemoral-, bilateral transtibial-, and bilateral transtibial/transfemoral-limb loss, comprising about 50 percent of all multiple-limb losses for both the Vietnam and OIF/OEF groups. Few previous reports exist of patients with multiple-limb loss because of battle wounds [2-4]. As reflected in our survey, those with war-theaterassociated limb loss often have other major injuries that complicate wound healing and rehabilitation $[4,20]$.

Comparison of the number of surgeries on the involved lower limbs in the Vietnam group and in the OIF/OEF group showed the OIF/OEF group had a greater number of surgeries following limb loss (2.5 \pm 4.3 and $5.5 \pm 6.1$, respectively). One reason for this result may be the differing treatment guidelines from each conflict. Open residual-limb dressings were changed without the use of the operating room during the Vietnam war [20]. Because of operating room availability, the ability to perform minor procedures in the operating room may be more frequent in the OIF/OEF group. A recent report documented reoperation of 25/213 (11.7\%) OIF/OEF servicemembers because of heterotopic bone ossification [21]. This finding was not reported for veterans with limb loss from the Vietnam war.

The Vietnam group had 39 more years of experience with post-limb-loss life, so unsurprisingly, veterans developed more age-related comorbidities, were less active, and had lower levels of general health. Several studies have shown the development of age-related comorbidities (cardiovascular disease, osteoarthritis) in those persons with traumatic-limb loss [22-23]. Melzer et al. reported knee osteoarthritis prevalence at 66 percent in the knee of the intact limb in a group with limb loss, whereas the osteoarthritis prevalence was 38 percent in the dominant limb in the controls for a 1.8 crude prevalence ratio [24]. Lemaire and Fisher reported osteoarthritis prevalence of 83 percent in the knee of the intact limb of a group with transtibiallimb loss and osteoarthritis prevalence of 50 percent in the comparison group, for a 1.7 crude prevalence ratio [25]. A case-control study by Norvell et al. assessing the prevalence of knee pain and osteoarthritis compared veterans with traumatic transtibial- and transfemoral-limb loss with veterans without limb loss [26]. The age- and average weight-adjusted prevalence ratio of knee pain for transtibial-limb loss compared with no limb loss was 1.3 (95\% confidence interval [CI] 0.7-2.1) for the knee of the intact limb. The standardized adjusted prevalence ratio of knee pain and knee osteoarthritis among the transfemoral amputation group compared with the no-amputation group for the intact limb was 3.3 (95\% CI, 1.5-6.3). The reported presence of arthritis was significantly higher in the Vietnam group than the OIF/OEF group (51\% vs $15 \%$, $p<0.01$ ).

In our study, the self-reported health status reported by the two groups was significantly different between those self-reporting the highest levels of wellness (excellent/very good), with 39 percent in the Vietnam group and 61 percent in the OIF/OEF group ( $p=0.01)$. Veterans and servicemembers in our study were far less likely to rank their health as excellent or very good than participants in the community-based National Health and Nutrition Epidemiologic Follow-Up Study or the medical 
outcomes study [14,27]. Low levels of self-reported health are consistent with advancing age and increasing chronic diseases and predict future health events, including hospitalization and mortality [28].

In this study, survey participants with multiple-limb loss reported that the level of functional ability was significantly lower in the Vietnam group. One-third of participants in the Vietnam group were nonambulators. By comparison, only 7 percent of the OIF/OEF group reported being nonambulatory $(p=0.002)$. While the OIF/OEF group currently reports high-impact activity, the servicemembers' functional level may more closely reflect the Vietnam group's functional capability as they age. Hoaglund et al. evaluated veterans with lower-limb loss from trauma or dysvascular disease and found 29 percent required assistance for ADL [29].

The presence of chronic back pain reported in our survey (19\% of Vietnam group and $21 \%$ of OIF/OEF group) was lower than reported in other groups of patients with limb loss. Smith et al. reported a prevalence of 71 percent for back pain in their series of older patients with non-war-theater-associated unilateral lower-limb loss from the VA hospital (VA Puget Sound Health Care System) and Harborview Medical Center, both in Seattle and Washington [30]. Hoaglund et al. reported that 7/13 (53.8\%) of veterans in the San Francisco Bay area with multiple-limb loss because of trauma or dysvascular disease reported back pain [29]. We used our composite pain score to assess the pain suffered globally, regardless of the source, and how pain may affect the use of prostheses. The scores did not distinguish between users of prostheses and nonusers. Different types of pain were frequently reported in veterans not using prostheses. We did not expect our composite mental health score to distinguish between prostheses users versus nonusers. Further research is needed to define the types of mental health issues and methods to measure them, because studies have shown significant mental health problems in injured servicemembers [31].

Phantom pain is also persistent in the Vietnam group (70\%) as well as the OIF/OEF group (69\%). Sherman and Sherman reported on the phantom-limb pain seen in a group of veterans whose limb losses were related to military service but not necessarily war-theater-associated. They found 85 percent reported significant phantom-limb pain an average of 29 years after initial limb loss [32]. Hoaglund et al. reported the presence of phantom pain in 10/13 (77\%) of VA patients with multiple-limb loss due to trauma [29]. The prevalence of phantom-limb and residual-limb pain (63\% and 76\%, respectively) reported by Smith et al. is similar to findings in both groups in our study [30].

PTSD is present in 25 percent of those with multiplelimb loss in the Vietnam group and 38 percent of those in the OIF/OEF group. Schlenger et al. reported on a cross section of 1,191 Vietnam veterans who were present "in theater," including those who sustained injury [33]. PTSD prevalence was 15 percent in men and 9 percent in women 15 or more years after military service. Part of the reason for the differences between OIF/OEF and Vietnam patients may be either that PTSD slowly resolves over time in these wounded servicemembers and veterans or that treatments have become more effective.

The general health section of the survey asks specifically about the presence of other health problems, including coronary artery disease, peripheral vascular disease, and diabetes. The OIF/OEF group with multiple-limb losses reported two comorbidities significantly more frequently than the Vietnam group: migraines $(19.7 \%$ and $6.9 \%$, respectively; $p=0.03)$ and TBI (32.8\% and $4.1 \%$, respectively; $p<0.01)$. Because TBI was not recognized as a clinical entity until the late 1990s [34], unsurprisingly, the Vietnam veterans do not report this condition frequently.

Prosthetic use is less frequent for those with multiplelimb loss compared with those with unilateral-limb loss. The loss of an additional limb decreases the proportion of patients wearing prostheses, compared with those with single-limb loss. A previous study of unilateral transtibial-limb loss sustained because of combat injuries in Vietnam shows that, on average, veterans used their prosthesis nearly 16 hours a day [35]. Similarly, 87 percent of patients with unilateral transfemoral-limb loss from the Vietnam war reported using a prosthesis for 14 hours a day [36]. Another study found 43.5 percent of those with bilateral transfemoral-limb loss used prostheses for ambulation an average of 12.9 years after injury [4]. After 28 years of follow-up, one-third of patients continued to use prostheses with some regularity. In our study, participants with bilateral transfemoral-limb loss had the highest frequency of not using prostheses (65\% in Vietnam group and $30 \%$ in OIF/OEF group). The combination of the difficulty ambulating with transfemoral-limb loss and aging contributes to this finding.

Of the 70 Vietnam veterans who received at least one prosthetic device, 20 (29\%) abandoned using them. Of 
the 20 abandoning prosthetic devices, most (80\%) have bilateral lower-limb loss. One patient in the Vietnam group (bilateral transradial) reported using approximately 90 prostheses over the past 42 years. This veteran works on a farm, and the prostheses are not sufficiently robust for these daily tasks. Those with upper-limb loss may also abandon prosthetic devices because of reliance on their contralateral arm [15]. Of the 59 OIF/OEF servicemembers who received prosthetic devices, only 3 (5\%) abandoned their devices and 67 percent have bilateral lower-limb loss. Abandonment is higher in the Vietnam group compared with the OIF/OEF group and may be related to the effects of age, comorbidities, decreased strength, and endurance.

This study has several limitations. The study design is cross-sectional in nature, so conclusions regarding causality or time sequence of events are limited. Future studies need to be done to follow the function and outcomes for these veterans and servicemembers with multiplelimb loss. Comparison of the Vietnam veterans to those from present-day wars is difficult, given the differing time since limb loss (3-year average for the OIF/OEF group) and 39-year average for the Vietnam group) and the differing ages of the two groups. Comparison of the two groups may not be valid for all categories, such as current prosthetic use. For example, those in the OIF/ OEF group have a shorter period of prosthetic use and have a far greater selection of prosthetic devices. Our survey participants are war-theater-injured individuals with limb loss; therefore, our results may not be generalizable to all populations with limb loss due to other etiologies (disease, congenital, noncombat).

\section{CONCLUSIONS}

Those with war-theater-associated multiple-limb loss are typically more severely injured; yet, their prognosis is good, based on the experiences of the Vietnam veterans with multiple-limb loss. These veterans established fulfilling lives, most are still employed, nearly 40 percent report very good to excellent health, and 67 percent are ambulatory. Most Vietnam veterans report continuing use of these prostheses for $>39$ years; yet painful prosthetic device fit and skin irritations are reported issues. Continued research in these two areas is needed. Other areas for future research to address are persistent phantom pain, back pain, PTSD, and depression. The VA needs to ensure that these individuals with multiple-limb loss are offered ongoing rehabilitation and prosthetic care to address the changes occurring over time to help them maintain overall function and a high quality of life.

\section{ACKNOWLEDGMENTS}

\section{Author Contributions:}

Study concept and design: L. V. McFarland, G. E. Reiber, P. J. Dougherty. Acquisition of data: P. J. Dougherty, L. V. McFarland, G. E. Reiber. Analysis and interpretation of data: L. V. McFarland, D. G. Smith, G. E. Reiber, A. Esquenazi, D. J. Blake, P. J. Dougherty. Drafting of manuscript: P. J. Dougherty, L. V. McFarland, D. G. Smith, A. Esquenazi, D. J. Blake, G. E. Reiber.

Critical revision of manuscript for important intellectual content: P. J. Dougherty, L. V. McFarland, D. G. Smith, A. Esquenazi, D. J. Blake, G. E. Reiber.

Obtained funding: G. E. Reiber.

Financial Disclosures: The authors have declared that no competing interests exist.

Funding/Support: This material was based on work supported by the VA Health Services Research and Development Service, grant IIR 05244, and a Career Scientist Award, Dr. Reiber, grant RCS 98-353. The views expressed in this article are those of the authors and do not necessarily reflect the position or policy of the VA or the DOD.

Institutional Review: The VA and DOD gave both institutional and human subjects approvals. Survey participants provided a waiver of consent.

Participant Follow-Up: The authors plan to inform the participants of the publication of this study.

\section{REFERENCES}

1. Brackett EG. Amputation service, A.E.F., care of the amputated in the United States. In: Ireland M, editor. The Medical Department of the United States Army in the World War. Washington (DC): United States Government Printing Office; 1927. p. 687-748.

2. Brown PW. Rehabilitation of bilateral lower-extremity amputees. J Bone Joint Surg Am. 1970;52(4):687-700. [PMID: 5479456]

3. Brown PW. Rehabilitation of the combat wounded amputee. In: Burkhalter WE, editor. Surgery in Vietnam. Orthopaedic Surgery. Washington (DC): Office of the Surgeon General and Center of Military History; 1994. p. 189-209.

4. Dougherty PJ. Long-term follow-up study of bilateral above-the-knee amputees from the Vietnam war. J Bone Joint Surg Am. 1999;81(10):1384-90. [PMID: 10535588]

5. Dougherty PJ, Carter PR, Seligson D, Benson DR, Purvis JM. Orthopaedic surgery advances resulting from World War II. J Bone Joint Surg Am. 2004;86-A(1):176-81. [PMID: 14711963] 
6. Ebrahimzadeh MH, Fattahi AS, Nejad AB. Long-term follow-up of Iranian veteran upper extremity amputees from the Iran-Iraq war (1980-1988). J Trauma. 2006;61(4):886-88.

[PMID: 17033556]

DOI:10.1097/01.ta.0000236014.78230.77

7. Wilson PD. Early weight-bearing in the treatment of amputations of the lower limbs. J Bone Joint Surg. 1922;4(2): 224-47.

8. Kirk NT. Amputations. Hagerstown (MD): W. F. Prior Co; 1924.

9. Dougherty PJ. Wartime amputations. Mil Med. 1993; 158(12):755-63. [PMID: 8108012]

10. Bellamy RF. Marine combat mortality. Mil Med. 2000; 165(12):ii-iii. [PMID: 11149073]

11. Bellamy RF. A note on American combat mortality in Iraq. Mil Med. 2007;172(10):i, 1023. [PMID: 17985758]

12. Puller LB. Fortunate son: The healing of a Vietnam vet. New York (NY): Grove Weidenfeld; 1991.

13. Reiber GE, McFarland LV, Hubbard S, Maynard C, Blough DK, Gambel JM, Smith DG. Servicemembers and veterans with major traumatic limb loss from Vietnam war and OIF/ OEF conflicts: Survey methods, participants, and summary findings. J Rehabil Res Dev. 2010;47(4):275-98.

14. Gailey R, McFarland LV, Cooper RA, Czerniecki J, Gambel JM, Hubbard S, Maynard C, Smith DG, Raya M, Reiber GE. Unilateral lower-limb loss: Prosthetic device use and functional outcomes in servicemembers from Vietnam war and OIF/OEF conflicts. J Rehabil Res Dev. 2010;47(4):317-32.

15. McFarland LV, Hubbard Winkler SL, Heinemann AW, Jones M, Esquenazi A. Unilateral upper-limb loss: Satisfaction and prosthetic device use in veterans and servicemembers from Vietnam and OIF/OEF conflicts. J Rehabil Res Dev. 2010; 47(4):299-316.

16. DeSalvo KB, Fan VS, McDonell MB, Fihn SD. Predicting mortality and healthcare utilization with a single question. Health Serv Res. 2005;40(4):1234-46. [PMID: 16033502] DOI:10.1111/j.1475-6773.2005.00404.x

17. Ware JE, Snow KK, Kosinski M, Gandek B. SF-36 health survey: Manual and interpretation guide. Boston (MA): The Health Institute, New England Medical Center; 1993.

18. Datta D, Selvarajah K, Davey N. Functional outcome of patients with proximal upper limb deficiency-Acquired and congenital. Clin Rehabil. 2004;18(2):172-77.

[PMID: 15053126]

DOI:10.1191/0269215504cr716oa

19. Laferrier JZ, McFarland LV, Boninger ML, Cooper RA, Reiber GE. Wheeled mobility: Factors influencing mobility and assistive technology in veterans and servicemembers with major traumatic limb loss from Vietnam war and OIF/ OEF conflicts. J Rehabil Res Dev. 2010;47(4):349-60.

20. Mayfield GW. Vietnam war amputees. In: Burkhalter WE, editor. Surgery in Vietnam: Orthopaedic surgery. Washing- ton (DC): Office of the Surgeon General and Center of Military History; 1994. p. 131-53.

21. Potter BK, Burns TC, Lacap AP, Granville RR, Gajewski DA. Heterotopic ossification following traumatic and combat-related amputations. Prevalence, risk factors, and preliminary results of excision. J Bone Joint Surg Am. 2007; 89(3):476-86. [PMID: 17332095]

DOI:10.2106/JBJS.F.00412

22. Modan M, Peles E, Halkin H, Nitzan H, Azaria M, Gitel S, Dolfin D, Modan B. Increased cardiovascular disease mortality rates in traumatic lower limb amputees. Am J Cardiol. 1998;82(10):1242-47. [PMID: 9832102]

DOI:10.1016/S0002-9149(98)00601-8

23. Struyf PA, Van Heugten CM, Hitters MW, Smeets RJ. The prevalence of osteoarthritis of the intact hip and knee among traumatic leg amputees. Arch Phys Med Rehabil. 2009;90(3):440-46. [PMID: 19254609]

DOI:10.1016/j.apmr.2008.08.220

24. Melzer I, Yekutiel M, Sukenik S. Comparative study of osteoarthritis of the contralateral knee joint of male amputees who do and do not play volleyball. J Rheumatol. 2001; 28(1):169-72. [PMID: 11196520]

25. Lemaire ED, Fisher FR. Osteoarthritis and elderly amputee gait. Arch Phys Med Rehabil. 1994;75(10):1094-99.

[PMID: 7944914]

DOI:10.1016/0003-9993(94)90084-1

26. Norvell DC, Czerniecki JM, Reiber GE, Maynard C, Pecoraro JA, Weiss NS. The prevalence of knee pain and symptomatic knee osteoarthritis among veteran traumatic amputees and nonamputees. Arch Phys Med Rehabil. 2005; 86(3):487-93. [PMID: 15759233]

DOI:10.1016/j.apmr.2004.04.034

27. Fryback DG, Lawrence WF, Martin PA, Klein R, Klein BE. Predicting quality of well-being scores from the SF36: Results from the Beaver Dam Health Outcomes Study. Med Decis Making. 1997;17(1):1-9. [PMID: 8994146] DOI:10.1177/0272989X9701700101

28. Gold M, Franks P, Erickson P. Assessing the health of the nation. The predictive validity of a preference-based measure and self-rated health. Med Care. 1996;34(2):163-77.

[PMID: 8632690]

DOI:10.1097/00005650-199602000-00008

29. Hoaglund FT, Jergesen HE, Wilson L, Lamoreux LW, Roberts R. Evaluation of problems and needs of veteran lowerlimb amputees in the San Francisco Bay Area during the period 1977-1980. J Rehabil Res Dev. 1983;20(1):57-71. [PMID: 6887067]

30. Smith DG, Ehde DM, Legro MW, Reiber GE, Del Aguila M, Boone DA. Phantom limb, residual limb, and back pain after lower extremity amputations. Clin Orthop Relat Res. 1999(361):29-38. [PMID: 10212593] DOI:10.1097/00003086-199904000-00005 
JRRD, Volume 47, Number 4, 2010

31. Hoge CW, Castro CA, Messer SC, McGurk D, Cotting DI, Koffman RL. Combat duty in Iraq and Afghanistan, mental health problems, and barriers to care. N Engl J Med. 2004; 351(1):13-22. [PMID: 15229303]

DOI:10.1056/NEJMoa040603

32. Sherman RA, Sherman CJ. Prevalence and characteristics of chronic phantom limb pain among American veterans. Results of a trial survey. Am J Phys Med. 1983;62(5):227-38. [PMID: 6624883]

33. Schlenger WE, Kulka RA, Fairbank JA, Hough RL, Jordan BK, Marmar CR, Weiss DS. The prevalence of post-traumatic stress disorder in the Vietnam generation: A multimethod, multisource assessment of psychiatric disorder. J Trauma Stress. 1992;5(3):333-63. DOI:10.1002/jts.2490050303
34. Consensus conference. Rehabilitation of persons with traumatic brain injury. NIH Consensus Development Panel on Rehabilitation of Persons with Traumatic Brain Injury. JAMA. 1999;282(10):974-83. [PMID: 10485684]

35. Dougherty PJ. Transtibial amputees from the Vietnam war. Twenty-eight-year follow-up. J Bone Joint Surg Am. 2001; 83-A(3):383-89. [PMID: 11263642]

36. Dougherty PJ. Long-term follow-up of unilateral transfemoral amputees from the Vietnam war. J Trauma. 2003; 54(4):718-23. [PMID: 12707534$]$ DOI:10.1097/01.TA.0000046260.16866.A9

Submitted for publication April 9, 2009. Accepted in revised form September 10, 2009. 